\title{
Fungal assembly of L-asparaginase using solid-state fermentation: a review
}

\author{
Sally NASER ${ }^{1,2}$; Wesameldin SABER ${ }^{3}$; Mohammad EL-METWALLY ${ }^{4, *}$; Mahmoud MOUSTAFA ${ }^{5,6}$; AtTalla EL-KOTT $^{5,7}$ \\ ${ }^{1}$ Life Sciences Department, College of Science and Literature Mahyel Aseer, King Khalid University, Abha, Saudi Arabia \\ ${ }^{2}$ Unit of Food Bacteriology, Central Laboratory of Food Hygiene, Ministry of Health, Branch in Zagazig, Sharkia, Egypt \\ ${ }^{3}$ Microbial Activity Unit, Department of Microbiology, Soils, Water and Environment Research Institute, Agricultural Research Center, Giza, Egypt \\ 4 Botany and Microbiology Department, Faculty of Science, Damanhour University, El-Behera, Egypt \\ ${ }^{5}$ Biology Department, College of Science, King Khalid University, Abha, 9004, Saudi Arabia \\ 6 Botany and Microbiology Department, Faculty of Science, South Valley University, Qena, Egypt \\ 7 Zoology Department, Faculty of Science, Damanhour University, El-Behera, Egypt
}

Key words: Immobilization, Statistical designs, Response surface methodology, Optimization

\begin{abstract}
Because of its antitumor therapeutic-activity, as well as its application in food industries to improve the quality, L-asparaginase has attracted considerable attention from several investigators. In recent years, fungi have occupied advanced rank among microorganisms in the production process of the enzyme. This review is spotting the light on the advantages of fungal enzyme and its applications in the food industry and medications. The solid-state fermentation was discussed as the wide alternative and most accepted biosynthesis technique. However, some lights were also spotted to the statistical experimental design of the fermentation process, mainly on the methodology of the response surface for L-asparaginase biosynthesis by fungi. Finally, the immobilization of the enzyme and the features of the widely used solid substrates for the maximization of the production process were explored.
\end{abstract}

\section{L-asparaginase}

The active bacterial form of the already used L-asparagine amidohydrolase, E.C. 3.5.1.1. (L-asparaginase), is a tetrameric enzyme, according to Kozak et al. (2002), all L-asparaginases consist of four identical subunits and exist in homotetrameric form having masses in the range of $140-150 \mathrm{kDa}$ (Aung et al., 2000), however, the structural aspects of fungal L-asparaginases are less explored compared to bacteria.

L-asparaginase deaminates the amide group located on the side chain of the nonessential amino acid, L-asparagine, yielding ammonia and L-aspartic acid (Zuo et al., 2015), through what is known as the L-asparaginase activity. Besides, some L-asparaginase preparations also exhibit Lglutaminase activity through a process called L-glutaminase side activity of L-asparaginase (Chan et al., 2014). Although the latter process is important against cancer cells, having a positive asparagine synthetase, it has been mentioned to have side effects during treatment such as hypersensitivity and immune inactivation (Chan et al., 2014; Narta et al.,

*Address correspondence to: Mohammad El-Metwally, mmmyco@ gmail.com

Received: 25 December 2019; Accepted: 21 April 2020
2007). Therefore, from a quality point, reducing the activity of glutaminase is desirable (Brumano et al., 2019).

As a foreign protein, the long-term therapy with L-asparaginase leads to toxicity to normal cells, causing a wide array of adverse effects, in terms of hypersensitivity (ranges from mild allergic reactions to anaphylactic shock), fever, skin rashes, hepatic dysfunction or hepatotoxicity, pancreatitis, diabetes, azotemia, leukopenia, neurological seizures or central nervous system dysfunction and abnormal coagulation of blood, leading to intracranial thrombosis or hemorrhage (Duval et al., 2002; Moola et al., 1994).

Hypersensitivity in patients treated with microbial Lasparaginase is a challenge. As a foreign protein, the prolonged administration of L-asparaginase induces the production of high titers of the corresponding serum IgG antibodies in patients; this, in turn, interferes with the therapeutic effect of the enzyme, resulting in anaphylactic shock and may also cause neutralization of drug effect. However, the intramuscular route lowers the hypersensitivity compared with intravenous administration (Duval et al., 2002; El-Naggar et al., 2017).

The impurities of the enzyme during production and purification is another reason for hypersensitivity, as the biochemical and kinetic properties of the enzyme vary with the microbial source and culture conditions such as temperature, substrate specificity, and $\mathrm{pH}$ (El-Naggar et al., 2017). 
L-asparaginases from Escherichia coli and Erwinia possess different immunological specificities, where the Erwinia enzyme had a shorter half-life in the blood, but it is considered less toxic than E. coli L-asparaginases and offers an important alternative therapy in the case of allergic reactions (Asselin et al., 1993; Pokrovskaya et al., 2012).

Additionally, the toxicity of some L-asparaginases preparations is partially attributable to the glutaminase activity of the enzyme (El-Naggar et al., 2017). Lglutaminase activity may cause a reduction in glutamine in the body that it limits the tolerable therapeutic dose of Lasparaginase. In this connection, Erwinia L-asparaginase is considered less toxic and is frequently employed in the event of allergic reactions to E. coli L-asparaginase (Hawkins et al., 2004; Konecna et al., 2004). However, such a catalyzation procedure is modulated along with two successive processes. Through the first phase, the nucleophilic fragment of L-asparaginase is motivated by a robust base and works on the amide carbon atom of $\mathrm{L}$ asparagine, generating intermediate of beta-acyl-enzyme. The second catalyzation phase is implemented in the presence of a water molecule by the attacking of the ester carbon created in the first step by the induced nucleophilic fragment (Cachumba et al., 2016; Shakambari et al., 2019).

To date, two diverse types of $\mathrm{L}$-asparaginases were identified. Type-I is the cytoplasmatic L-asparaginase, which is located in the cytoplasm region and characterized by the low-affinity to the substrate (L-asparagine). On the other side, type-II is the periplasmic L-asparaginase, which is located in the periplasmic region, has high substrate-affinity, and is activated during anaerobiosis. Because of the enzyme's antitumor activity is related to the affinity for Lasparagine, only type-II is the specifically used type in the therapeutic medication (Shakambari et al., 2019; Souza et al., 2017; Yun et al., 2007).

\section{Applications of L-asparaginase}

There is a broad utilization of L-asparaginase in various food manufacturing as a processing aid to reduce the acrylamide content, medical and pharmaceutical purposes such as cancer-curing as auxiliary treatment. However, all ways of using the enzyme are vital and share directly in the health welfare of human beings.

\section{Cancer curing}

Of the most critical uses of the enzyme, L-asparagine is a necessary amino acid for protein synthesis, which is produced by the aid of asparagine synthetase. Lacking asparagine synthetase in certain tumor cells, causes the inability of such tumor cells to synthesize L-asparagine. This, in turn, leads to failure in cell growth and multiplication. Such tumor cells can be selectively killed by destroying L-asparagine through treatment with L-asparaginase (Pritsa et al., 2001). That is why L-asparaginase, as a medication, is an operative chemotherapeutic mediator in a wide array of tumors, especially acute lymphoblastic leukemia and lymphosarcoma.

Moreover, L-asparaginase can be injected subcutaneous, intramuscular, or intravenous without the development of any tissue irritation, representing a practical advantage of treatment by L-asparaginase over most of the other chemotherapy means (Narta et al., 2007).

\section{Food quality enhancer}

During food processing, acrylamide $\left(\mathrm{C}_{3} \mathrm{H}_{5} \mathrm{NO}\right.$, MW 71.08 $\mathrm{g} / \mathrm{mol}$ ), which is also known as ethylene carboxamide, 2-propenamide, propenamide, propanoic acid amide, or acrylic acid amide, is produced (Cachumba et al., 2016). Acrylamide is formed from L-asparagine and a reducing sugar such as glucose or fructose, in starchy food products, during high-temperature cooking, including frying, baking and roasting through a series of reactions, known as Maillard reactions. However, this phenomenon does not occur in boiled food (El-Naggar et al., 2017; Pedreschi et al., 2011).

During food manufacturing, L-asparaginase is applied as a processing aid to lessen the formation and/or remove acrylamide. Acrylamide is a probable human carcinogen and can be present in other foods such as coffee and baby food products, as well as in starchy food products. Recently, submission of L-asparaginase before frying or baking food process degrades not less than $88 \%$ of the L-asparagine content in the initial feedstock, this, in turn, reduces over $99 \%$ of the acrylamide level in the processed products without impairing their taste and odor properties (Cachumba et al., 2016).

\section{Trade names of some commercial L-asparaginase}

Some of the brand names of the commercially available bacterial L-asparaginase are Elspar, Pegaspargase, PEGasparaginase, Oncaspar, Crisantaspase, and Colaspase. To the best of our knowledge, there is no commercial preparation of fungal L-asparaginases. L-asparaginases, as a processing aid in the manufacture of food, are marketing under the brand names Acrylaway and PreventASe.

\section{Why Fungi?}

$\mathrm{L}$-asparaginase is broadly disseminated in nature, being found in microbes as well as plants and tissues of fishes, birds, and mammals such as liver, kidneys, pancreas, brain, spleen lungs and ovary or testes. Nevertheless, because of its wide presence in assortments of microorganisms, microbial Lasparaginase is a better source of enzyme than other living organisms (Cachumba et al., 2016), considering, likewise, the microbial ability to grow easily on rather simple and modest substrates (Lopes et al., 2017; Souza et al., 2017).

However, the prokaryotic microbes, such as bacteria, usually accompanies with some problems during patient treatment such as hypersensitivity and immune inactivation (Chan et al., 2014; Narta et al., 2007). The toxic side effects of some currently used clinical medications of bacterial origin have necessitated the search for alternative sources of L-asparaginase (Mishra, 2006). Instead, eukaryotic sources such as filamentous fungi, on the other side, have revealed better compatibility with the human body, and therefore extensively explored for L-asparaginase (Dange and Peshwe, 2015). Moreover, the filamentous fungi possess an antitumor property with a non-toxic effect (Mishra, 2006). 
Another merit of using fungi for bioproduction of $\mathrm{L}$-asparaginase is related to water requirement. Based on the classification of water activity (a measure of the available water in a substrate), fungi were primarily designated as appropriate for solid-state fermentation in contrast to bacteria that have high water activity requirements (Cachumba et al., 2016).

Recently, the eukaryotic fungal genera Aspergillus, Penicillium, and Fusarium have been explored as L-asparaginase producers (Cachumba et al., 2016; Mishra, 2006). Furthermore, the recombinant L-asparaginase of Aspergillus niger and A. oryzae has already been successfully utilized for the lessening of acrylamide formation in some foods (Pedreschi et al., 2011).

Asparaginolytic fungi grow under and can be obtained from various environmental conditions. In this connection, fungi with asparaginolytic action belonging to the genera of Alternaria, Chaetomium, Cladosporium, Colletotrichum, Curvularia, Nigrospora, Paecilomyces, Phaeotrichoconis, Phoma and Pithomyces were isolated from marine environments and endophytes seaweed (Thirunavukkarasu et al., 2011), and recently, Fusarium culmorum was isolated from tropical soil (Meghavarnam and Janakiraman, 2017).

\section{Solid-State Fermentation}

Solid-state or solid-substrate fermentation (SSF) is a biomolecule manufacturing procedure, during which a solid-substrate is inoculated with microbes in the lack or nearly absence of free-flowing water in the solid substrate, then incubated in a temperature-controlled condition for a definite time (Kapilan, 2015).

The SSF technique has many industrial applications and recently gained importance and popularity in the manufacturing of numerous microbial biomolecules and several bioactive metabolites of commercial value such as enzymes, antibiotics, flavoring compounds, and many other secondary metabolites as well as microbial biomass, which are utilized in various life aspects, e.g., pharmaceutical, food, animal feeds, cosmetics, fuel, and textile industries (Kapilan, 2015; Mitchell et al., 2006).

\section{Scaling-up of SSF}

The scaling-up of the SSF requires the involvement of sequential phases. For effective scaling-up, enough data must be available, practically, the number of stages is generally determined by the product type and the earlier experiences of the process. Based on fermenter size, four graded kinds of systems appear to be applicable for the development of SSF as follows (Lonsane et al., 1992; Mitchell et al., 2006):

I. Flask level with a working capacity of 50-1000 g. This level is for choosing the experimental variables for optimization of the culturing process and performed in a short time and at a low cost.

II. Laboratory fermenter with a working capacity of 5-20 $\mathrm{kg}$, during which several fermentation aspects are studied for standardization of various parameters such as aeration, agitation, and downstream processing, as well as aeration rate, biomass formation, and product biosynthesis profiles. Through this level of SSF, control strategies and instruments are commercially optimized and the economics of the process is evaluated.

III. For confirmation of laboratory fermenters, the pilot fermenter level with a working capacity of 50-5000 kg is applied. This level is for testing the physicochemical characterization and/or toxicity for the determination of the viability of the process before the marketing of the final product.

IV. The final development level of SSF with a financial return is performed using a production fermenter with a working capacity of 25-1000 tones. The process is the ultimate stage of the investments made so far on the SSF system.

\section{Merits of SSF technique}

The technology of SSF for culturing of fungi is the best alternative to the submerged fermentation technique (SMF) used predominantly for industrial purposes. Several merits of SSF were reported over the traditional SMF. These advantages include; low energy inputs, easier downstream processing with lower catabolic repression, high volumetric productivity, and higher concentration and reasonable stability of the products, and finally, no obligation for complex machinery that, hence, reduces energy demand. Additionally, SSF uses economic and simple media, mainly due to the use of cheap and abundantlyavailable of industrial and agricultural wastes as substrates (Kapilan, 2015; Parekh et al., 2000).

The economy of space needed in processing is another advantage, which is owing to the lesser space for fermentation, the compactness of the fermentation vessel, and the lower water activity, which also minimizes the opportunity of contamination (Kapilan, 2015).

On the industrial scale, SSF requires lower capital and low recurring expenditures, a lesser solvent volume needed for product recovery; superior yields; absence of foam build-up; and easier control of contaminants due to the low moisture level in the production unit (Kapilan, 2015; Pandey et al., 1996). At the end of the fermentation, enzymes can be extracted from the solid substrate by simply infiltrating the bioreactor with the appropriated buffers, which is an easy and economical operation (Pandey et al., 1996).

The low water used in SSF results in low production of effluents and reduces the possibility of contamination with bacteria and/or yeasts. This, in turn, reduces the cost of sterilization (Mishra, 2006). Finally, compare to synthetically designed SMF technique, interestingly, so far there is no standard scale to compare product yields in SSF and SMF in convincing terms, and the exact reason for higher yield titers in SSF microbial cultures is not well known. The proposed and logic reason is that SSF is closely resembling the natural habitat and the environmental circumstances required for the microbial growth, as well as, the substrates in SSF serve as an anchorage for fungal hyphae, all these are possible reasons for the higher productivity of the fungi under SSF conditions (Mishra, 2006).

\section{Demerits of SSF technique}

Inevitably, there are some fermentation obstacles when using SSF, i.e., (1) the accumulation of nutrients within the 
microbial cells during the initial growing phase and the need for the production of substrate-hydrolyzing enzymes may delay the production of the target biomolecule, therefore continuous stirring for better mixing the medium components is required and can solve such issue; (2) poor distribution of temperature, nutrients, and oxygen in the medium that could be overcome by occasional stirring the fermented medium, as well as following-up the temperature, oxygen, and carbon dioxide, and use these to control the system by forced aeration that can, at the same time, control the temperature; and (3) the accumulation of the toxic substances, which might have prohibited the growth of the microbial cells and caused death, for dealing with such topic, it is urgent to perform mathematical models for effective prediction and optimization of the fermentation process. Such modeling processes of medium gradients capable of removing metabolic heat as well (Kapilan, 2015; Manan and Webb, 2017; Nee'nigam and Pandey, 2009). One major problem is the medium sterilization on the large-scale production, which lasts for 3-6 h compared with the batch laboratory-scale sterilization mode (15 $\mathrm{min}$ at $121^{\circ} \mathrm{C}$ ). The large-scale sterilization mode poses many problems such as physicochemical alterations in the medium, thermal degradation of essential nutrients, the formation of toxic compounds, and nutrient damage. The heating time to attain the desired temperature of sterilization and the poststerilization cooling to incubation temperature is another problem. However, the principle of continuous sterilization, which involves a high temperature for a short time, is comparatively easy to scale-up. The probability of thermal destruction of nutritive constituents of the medium is also lower (Lonsane et al., 1992; Mitchell et al., 2006).

\section{Natural vis inert solid-supports}

SSF is a proper selection, particularly for fungal culturing, during which, the non-soluble solid material is acting as physical support for the microbe. Two major kinds of solid supports could be identified, depending on the nature of the solid phase used. This solid material could be either a naturally occurring solid substrate (such as residues of agriculture, as wheat bran, or of industry, as wastes of paper and pulp industries) or inert support (pozolano, amberlite and polyurethane foam), both have been adapted for the development of an economic fermentation medium. Whatever the type of the used solid phase, it is essential to reproduce the situations of low water activity and high oxygen transference rate (Meghavarnam and Janakiraman, 2017; Ooijkaas et al., 2000).

Regarding the first kind of solid phase, the SSF operation generally employs a natural raw resource as a carbon and energy reservoir to serve as both solid support and substrate to produce the target molecules. Sometimes it requires a specific pretreatment to qualify the fermentation conditions and simulate the natural growth of the microbes (Meghavarnam and Janakiraman, 2017).

The other type of solid phase of SSF is the employment of inert material to act as a solid matrix or support for fungal growth, consequently, it requires supplementing the nutrients in a solution containing necessary minerals as well as a carbon source. This kind of solid-phase typically serves only as an anchor point for the microorganism (Ooijkaas et al., 2000).

Owing to its more definite system, carrying out SSF on inert supports poses plenteous advantages in comparison to SSF on natural substrates. These advantages include; It allows adequate control in the design and process parameters of the production medium (Gutiérrez-Rojas et al., 1995), and the modeling is more easily established because all concentrations of the nutrients in the production medium are definitely known (Barrios-González and Mejía, 1996; Zhu et al., 1994). That is why inert materials have been often used for studying modeling or other fundamental aspects of SSF.

Regarding the end-product, SSF using inert supports has less complicated product recovery, since, the target biomolecules can be effortlessly separated from the inert support, and therefore products can be obtained with fewer impurities (Ooijkaas et al., 2000), so, the inert support can be separated and reused. Contrarily, while extracting the product after fermentation of naturally occurring raw materials, along with the product, numerous other watersoluble components from the substrate also leach out and may pose difficulties in the purification process.

\section{Cell Immobilization}

Another complementary role of inert solid supports is to immobilize the cells of microorganisms during fermentation. Microbial cell immobilization improves L-asparaginase yield by supporting the long-term continuous production under such conditions, this kind of fermentation serves as cell immobilization and inert solid matrix for microbial growth as well, in which the microbial cells are attached to and kept safe in the matrix pores (Kar and Ray, 2008). This approach of cell immobilization technology improves fermentation and production processes because of the continual fermentation over a prolonged period, enhancing reactor productivity and ensuring higher efficiency of catalysis (Kar and Ray, 2008; Kattimani et al., 2009).

However, the appropriate choice of immobilization procedures and supporting matrix are both required to minimalize the inconveniences that may be accompanied by the immobilization process. That is why the most extensively utilized immobilization method is the entrapment technique, on the other side, the adsorption method has two advantages, namely, simplicity and enhanced physiological fermentation conditions (Pramod and Lingappa, 2008).

Of the most multipurpose matrix worldwide are polyurethanes. In comparison to other matrices, it is the most successful matrix. It has several uses in various life aspects. Immobilization of microbial cells in polyurethane foam has several advantages, including endurance to organic solvents and microbial attack, high mechanical strength, easy handling, renewability, and cost-effectiveness. Besides being perfect support for enzyme immobilization, it has been found to be appropriate in the various biochemical and biotechnological fields as well (Kar and Ray, 2008; Kattimani et al., 2009).

Immobilization of microbial cells was reported to positively induce the bio-secretion of L-asparaginase by both 
bacteria and fungi as well. Immobilization of Streptomyces gulbargensis cells on a matrix of polyurethane foam gained higher L-asparaginase biosynthesis compared to that of the free-cell system during the same period of fermentation. Again, in the long-term, the stability and reusability of the matrix are other value-added advantages (Kattimani et al., 2009). Regarding fungi, biosynthesis of L-asparaginase using the immobilized Aspergillus terreus on sponge cubes gained higher enzyme production by 1.33 -fold compared to that of the free-cell system during the same period of fermentation. Repeated reuse of the adsorbed cells achieved the maximum enzyme-specific activity after three cycles of fermentation (Farag et al., 2015).

\section{Statistical Designs of Production Trials}

Exploring and evaluating the appropriate nutritional medium components and environmental conditions for microbial enzyme production is a significant step for bioprocess development. Two main approaches are applied in the experimental design used for L-asparaginase production.

Optimization of the fermentation process using the onefactor-at-a-time approach is the traditional method used to test individual fermentation parameters, however, it is timeconsuming, laborious, tedious, and might lead to misinterpretations of results (Narayana et al., 2008).

In contrast, statistically planned experiments effectively and accurately challenge the problem, which minimizes the error and determines the significance of each parameter, single and in combination with the other tested factor(s), at the various concentrations for maximization of the overall productivity, and can be simply expressed in a mathematical equation. Statistical methods are rapid and reliable, and can also reduce the total number of experimental trials tremendously. Therefore, the obtained results are achieved in an economical manner (El-Naggar et al., 2017; Shakambari et al., 2019).

\section{Screening the significant factors}

The initial step in the optimization procedure is to choose the significant factors. The design matrix of Plackett-Burman is an appropriate strategy in screening the factors affecting the biosynthesis of the target metabolite, it is very vital to test as many factors as possible, and to identify the significance ones. Besides, Plackett-Burman design offers a fast screening procedure and mathematically figures the relative importance and significance of many factors in one experiment, which is time-saving and maintains convincing information on each component (Abdel-Fattah and Olama, 2002; Shakambari et al., 2019).

For example, among 15 tested factors, casein hydrolysate, corn steep liquor, and $\mathrm{pH}$ were designated as the significant issues improving L-asparaginase biosynthesis using one experimental trial (Abdel-Fattah and Olama, 2002). Another, of 16 screened variables, the Plackett-Burman design determined soybean + wheat bran, L-asparagine, and $\mathrm{K}_{2} \mathrm{HPO}_{4}$ as the significant independent variables (El-Naggar et al., 2017). However, the interactions among factors are not included in such screening procedures, so the interactions of the most effective factors are to be selected for further optimization, while those having no significant effect on the bioproduction process may be eliminated during the next optimization process (Abdel-Fattah and Olama, 2002).

\section{The methodology of response surface (RSM)}

Following the definition of the significant variables, the subsequent phase of L-asparaginase biosynthesis is the optimization of the process of the selected important factors. RSM is an effectual approach that evaluates and estimates the effective factors and their interaction. These designs convert the bioprocess factor into a mathematical model. Where the resulting output in terms of yield is analyzed statistically for their importance, and the biological production process then can be correlated with a mathematical equation in a quadratic manner that predicts where the optimum is likely to be located (Shakambari et al., 2019).

Of the several designs of RSM, Box-Behnken is used usually when fewer design points (3 levels per factor) are available, hence it is less expensive to run in comparison to other designs such as the central composite design (CCD), where, CCD can have up to 5 levels for each factor, and include runs where all factors are at their extreme levels (Da Cunha et al., 2018). The experimental designs of BoxBehnken (Abdel-Fattah and Olama, 2002) and CCD (ElNaggar et al., 2017) were successfully applied to maximize the production of L-asparaginase. One recent study stated a $57 \%$ increment in L-asparaginase activity when applying the optimized conditions obtained from RSM in comparison with the productivity obtained in the method of "one factorat-a-time" (Da Cunha et al., 2018).

The artificial neural network (ANN) is another optimization procedure. Investigations reported that the ANN was more precise and was realized to be more effective than RSM alone. ANN is based on machine learning techniques by mimicking the different aspects of biological information processing for data modeling, and so proved to be a useful tool for the optimization of medium fermentation (Baskar and Renganathan, 2011; Gurunathan and Sahadevan, 2011).

\section{Suitability of SSF for L-asparaginase production}

There are main vital aspects, which should be considered, in general, for the improvement of any bioprocess in SSF. Of these factors, the choice of the appropriate microorganism and the substrate, optimization of process conditions, and finally, the isolation and purification of the resulted bioproduct. Other important factors involved in SSF are the substrate, size of substrate particle, water activity, temperature, moisture, $\mathrm{pH}$, agitation, and aeration (Brumano et al., 2019). However, these factors are aggressively correlated and must be handled collectively as one factor.

Regarding the substrate as the key factor in the production process, SSF utilizes abundantly available agroindustrial residues. The next Tab. 1 shows some of the substrates used for L-asparaginase production under solidstate fermentation, the corresponding amount of the enzyme, fermentation period, and fungal strains used.

Practically, in relation to the selection of the substrate, there are two major considerations; the first one is using a 
TABLE 1

The most widely used substrates for the production L-asparaginase under solid-state fermentation by fungi and their corresponding yield

\begin{tabular}{|c|c|c|c|c|}
\hline Fungus & Substrate & $\begin{array}{l}\text { Production unit per } \\
\text { gram substrate }\end{array}$ & $\begin{array}{l}\text { Fermentation } \\
\text { period }(\mathrm{h})\end{array}$ & Reference \\
\hline $\begin{array}{l}\text { Aspergillus tubingensis } \\
\text { IBBL1 }\end{array}$ & $\begin{array}{l}\text { A mixture of cottonseed cake, wheat } \\
\text { bran and red gram husk }\end{array}$ & 20.58 & 120.0 & Doriya and Kumar (2018) \\
\hline Aspergillus niger LBA 02 & Passion fruit peel flour & 3746.78 & 48.0 & Da Cunha et al. (2018) \\
\hline $\begin{array}{l}\text { Fusarium culmorum } \\
\text { (ASP-87) }\end{array}$ & Soybean meal and wheat bran & 18.91 & 144.0 & $\begin{array}{l}\text { Meghavarnam and } \\
\text { Janakiraman (2017) }\end{array}$ \\
\hline A. terreus MTCC1782 & Cornea and cauliflower stalk & 567.16 & 96.0 & Aparna and Raju (2015) \\
\hline Aspergillus niger LBA 02 & $\begin{array}{l}\text { A mixture of wheat bran, soybean } \\
\text { meal and cottonseed meal }\end{array}$ & 89.22 & 96.0 & Dias et al. (2015) \\
\hline A. melleus AVNR-1 & Coconut oil cake and red gram husk & 109.55 & 168.0 & Supriya et al. (2015) \\
\hline $\begin{array}{l}\text { Beauveria bassiana } \\
\text { (MSS18/41) }\end{array}$ & Wheat bran & 90.00 & 96.0 & Nageswara et al. (2014) \\
\hline A. niger $\mathrm{C} 4$ & Black sesame oil cake & 340.20 & 168.0 & Uppuluri et al. (2013) \\
\hline A. niger & Dry feedstock on ginger oil cake & 88.00 & - & Vivekananda et al. (2013) \\
\hline A. niger & Groundnut oil cake & 21.70 & - & Sreenivasulu et al. (2009) \\
\hline A. niger & Glycine max bran & 40.90 & 96.0 & Mishra (2006) \\
\hline
\end{tabular}

specific substrate, which requires suitable value-addition and/ or disposal. The second could be related to the goal of producing a specific product from the selected substrate. So, in the latter one, it would be necessary to explore numerous substrates to select the most appropriate one. Similarly, it would be important to screen microorganisms to select the most suitable one.

Although numerous agro-industrial residues can be used for SSF, the main factor involved in substrate selection for enzyme production is mostly associated with the availability and price of the substrate. Anyhow, the solid substrate must supply the essential nutrients and assist in the growth of microbes and, additionally, provides support for the cell's growth (Kapilan, 2015). SSF differs from SMF culturing since the product is formed by the microbes at the surface of the solid substrate particle, which have a low moisture content or near to it, therefore, precautions of dryness must be taken into account, where water plays an important role in the physical and chemical properties of the solids and products as well, which affect the performance of the overall process productivity (Brumano et al., 2019).

The size of substrate particles controls its surface area, which affects the substrate to the substrate-volume ratio. As the particle size of the substrate decreases, the ratio of surface area to volume increases. Besides, space is also determined by the substrate particle size, which further affects the rate of oxygen transfer. When the particle size is small, the microbes get a larger surface area for its growth. Whereas, very small particles lead to the reduction in growth and clumping of substrates in comparison to particles larger in size, which provides a better exchange of oxygen and heat. Hence, a suitable surface area would ease microbial assimilation, oxygen diffusion, and nutrient absorption, leading to better enhancement of microbial growth and mass transformation (Da Cunha et al., 2018;
Souza et al., 2017; Thomas et al., 2013). That is why, in some cases, incorporating fibrous substrate or porous coarsely granulated substrate to the SSF medium is important to ease the free movement of air and better transfer of oxygen (Thomas et al., 2013). In this respect, paddy husk is a good natural substrate, having a satisfactory porous structure to produce L-asparaginase (Mohan Kumar et al., 2013). Another determining factor, cultivating on heterogeneous substrates requires proficiency to keep the production process at its optimal performance (Thomas et al., 2013).

\section{Current Situation and Future Vision}

The technology of SSF was traditionally used for producing various metabolites such as biosurfactants, organic acids, antibiotics, aroma compounds, and intensively, enzymes; actually, SSF received more attention due to the wide number of applications for metabolite production or remediation objectives that can be realized using this system (Lizardi-Jiménez and Hernández-Martínez, 2017).

However, almost $93 \%$ of the total worldwide patent applications regarding SSF (2178) appeared after 2001; since then, there was a continual rise in the number of its applications. According to the Patent Cooperation Treaty, the distribution of SSF related patent applications, a system used to ease international applications, China is the country with more patent applications in the world (54\%), with a large margin to Japan (8\%), South Korea (7\%), United States $(7 \%)$, European Union (7\%), Russia (7\%) and others (Soccol et al., 2017).

Fungi are newly involved in L-asparaginase production, although its L-asparaginases derived have been less studied than their bacterial counterparts, and they have not been included in any commercial formulation, it is expected to 
occupy a unique position in the next era. Apart from bacteria, fungi are able to produce and secrete the enzyme extracellularly, which is easier to purify than the intracellular enzyme produced by bacteria, and this can decrease the overall costs of production, in addition to the lower chance in the immunological reactions, once fungi are eukaryotes and their enzymes are more similar to human proteins than prokaryote proteins (Goncalves et al., 2016; Soccol et al., 2017).

In spite the growing interest in the production and purification of L-asparaginase of fungi, there are some hidden problems regarding structural aspects of fungal Lasparaginase, which is less explored compared to bacteria, the lighting side of the explorations of fungal enzyme brought good news about enzyme with novel properties (Vala and Dave, 2016). So, the expectations are very optimistic regarding the growing production then transformation towards the fungal source of enzyme in the near future.

Finally, the biosynthesis of L-asparaginase, depending on the SSF using appropriate fungi, has been considerably developed in the last decades. Therefore, it is expected to achieve promising progress in the next years, especially with the condense application of optimization of process parameters using statistical approaches.

Funding Statement: The authors would like to thank the Deanship of Scientific Research at King Khalid University, Abha, KSA for funding this work under Grant number (G.R.P/150/40).

Conflicts of Interest: The authors declare that they have no conflicts of interest to report regarding the present study.

\section{References}

Abdel-Fattah YR, Olama ZA (2002). L-asparaginase production by Pseudomonas aeruginosa in solid-state culture: evaluation and optimization of culture conditions using factorial designs. Process Biochemistry 38: 115-122. DOI 10.1016/ S0032-9592(02)00067-5.

Aparna C, Raju KJ (2015). Optimization of process parameters for Lasparaginase production by Aspergillus terreus MTCC1782 under solid state fermentation using mixed substrate. International Journal of Research in Engineering and Technology 4: 354-360.

Asselin BL, Whitin JC, Coppola DJ, Rupp IP, Sallan SE, Cohen HJ (1993). Comparative pharmacokinetic studies of three asparaginase preparations. Journal of Clinical Oncology 11: 1780-1786. DOI 10.1200/JCO.1993.11.9.1780.

Aung HP, Bocola M, Schleper S, Röhm KH (2000). Dynamics of a mobile loop at the active site of Escherichia coli asparaginase. Biochimica et Biophysica Acta-Protein Structure and Molecular Enzymology 1481: 349-359. DOI 10.1016/S0167-4838(00)00179-5.

Barrios-González J, Mejía A (1996). Production of secondary metabolites by solid-state fermentation. Biotechnology Annual Review 2: 85-121.

Baskar G, Renganathan S (2011). Statistical and evolutionary optimisation of operating conditions for enhanced production of fungal L-asparaginase. Chemical Papers 65: 798-804. DOI 10.2478/s11696-011-0072-8.
Brumano LP, Da Silva FVS, Costa-Silva TA, Apolinário AC, Santos JHPM, Kleingesinds EK, Monteiro G, Rangel-Yagui CDO, Benyahia B, Junior AP (2019). Development of L-asparaginase biobetters: current research status and review of the desirable quality profiles. Frontiers in Bioengineering and Biotechnology 6: 212. DOI 10.3389/fbioe.2018.00212.

Cachumba JJM, Antunes FAF, Peres GFD, Brumano LP, Dos Santos JC, Da Silva SS (2016). Current applications and different approaches for microbial 1-asparaginase production. Brazilian Journal of Microbiology 47: 77-85. DOI 10.1016/j.bjm.2016.10.004.

Chan WK, Lorenzi PL, Anishkin A, Purwaha P, Rogers DM, Sukharev S, Rempe SB, Weinstein JN (2014). The glutaminase activity of L-asparaginase is not required for anticancer activity against ASNS-negative cells. Blood 123: 3596-3606. DOI 10.1182/blood-2013-10-535112.

Da Cunha MC, Silva LC, Sato HH, De Castro RJS (2018). Using response surface methodology to improve the Lasparaginase production by Aspergillus niger under solidstate fermentation. Biocatalysis and Agricultural Biotechnology 16: 31-36. DOI 10.1016/j.bcab.2018.07.018.

Dange V, Peshwe S (2015). Purification and biochemical characterization of L-asparaginase from Aspergillus niger and evaluation of its antineoplastic activity. International Journal of Science and Research 4: 564-569.

Dias FFG, de Castro RJS, Ohara A, Nishide TG, Bagagli MP, Sato HH (2015). Simplex centroid mixture design to improve Lasparaginase production in solid-state fermentation using agroindustrial wastes. Biocatalysis and Agricultural Biotechnology 4: 528-534.

Doriya K, Kumar DS (2018). Solid state fermentation of mixed substrate for L-asparaginase production using tray and inhouse designed rotary bioreactor. Biochemical Engineering Journal 138: 188-196.

Duval M, Suciu S, Ferster A, Rialland X, Nelken B, Lutz P, Benoit Y, Robert A, Manel AM, Vilmer E (2002). Comparison of Escherichia coli-asparaginase with Erwinia-asparaginase in the treatment of childhood lymphoid malignancies: results of a randomized European Organisation for Research and Treatment of Cancer-Children's Leukemia Group phase 3 trial. Blood 99: 2734-2739. DOI 10.1182/blood.V99.8.2734.

El-Naggar NEA, Moawad H, Abdelwahed NA (2017). Optimization of fermentation conditions for enhancing extracellular production of L-asparaginase, an anti-leukemic agent, by newly isolated Streptomyces brollosae NEAE-115 using solid state fermentation. Annals of Microbiology 67: 1-15. DOI 10.1007/s13213-016-1231-5.

Farag AM, Hassan SW, Beltagy EA, El-Shenawy MA (2015). Optimization of production of anti-tumor L-asparaginase by free and immobilized marine Aspergillus terreus. Egyptian Journal of Aquatic Research 41: 295-302. DOI 10.1016/j.ejar.2015.10.002

Goncalves AB, Maia ACF, Rueda JA, De Figueiredo Conte Vanzela AP (2016). Produção fúngica da enzima antileucêmica Lasparaginase: da triagem ao desenvolvimento de um meio de cultivo. Acta Scientiarum-Biological Sciences 38: 387394. DOI 10.4025/actascibiolsci.v38i4.32993.

Gurunathan B, Sahadevan R (2011). Design of experiments and artificial neural network linked genetic algorithm for modeling and optimization of L-asparaginase production by Aspergillus terreus MTCC 1782. Biotechnology and Bioprocess Engineering 16: 50-58. DOI 10.1007/s12257-010-0119-7.

Gutiérrez-Rojas M, Cordova J, Auria R, Revah S, Favela-Torres E (1995). Citric acid and polyols production by Aspergillus 
niger at high glucose concentration in solid state fermentation on inert support. Biotechnology Letters 17: 219-224. DOI 10.1007/BF00127992.

Hawkins DS, Park JR, Thomson BG, Felgenhauer JL, Holcenberg JS, Panosyan EH, Avramis VI (2004). Asparaginase pharmacokinetics after intensive polyethylene glycolconjugated L-asparaginase therapy for children with relapsed acute lymphoblastic leukemia. Clinical Cancer Research 10: 5335-5341. DOI 10.1158/1078-0432.CCR-04-0222.

Kapilan R (2015). Solid state fermentation for microbial products: a review. Archives of Applied Science Research 7: 21-25.

Kar S, Ray RC (2008). Statistical optimization of a-amylase production by Streptomyces erumpens MTCC, 7317 cells in calcium alginate beads using response surface methodology. Polish Journal of Microbiology 57: 49-57.

Kattimani L, Amena S, Nandareddy V, Mujugond P (2009). Immobilization of Streptomyces gulbargensis in polyurethane foam: a promising technique for L-asparaginase production on. Iranian Journal of Biotechnology 7: 199-204.

Konecna P, Klejdus B, Hrstková H (2004). Monitoring the asparaginase activity and asparagine levels in children with acute lymphoblastic leukaemia treated with different asparaginase preparations. Scripta Medica 77: 55-62.

Kozak M, Borek D, Janowski R, Jaskólski M (2002). Crystallization and preliminary crystallographic studies of five crystal forms of Escherichia coli L-asparaginase II (Asp90Glu mutant). Acta Crystallographica Section D: Structural Biology 58: 130-132. DOI 10.1107/S0907444901016663.

Lizardi-Jiménez MA, Hernández-Martínez R (2017). Solid state fermentation (SSF): diversity of applications to valorize waste and biomass. 3 Biotech 7: 44.

Lonsane B, Saucedo-Castaneda G, Raimbault M, Roussos S, ViniegraGonzalez G, Ghildyal N, Ramakrishna M, Krishnaiah M (1992). Scale-up strategies for solid state fermentation systems. Process Biochemistry 27: 259-273. DOI 10.1016/ 0032-9592(92)85011-P.

Lopes AM, Oliveira-Nascimento LD, Ribeiro A, Tairum CA Jr, Breyer CA, MaD Oliveira, Monteiro G, Souza-Motta CMD, Magalhães PDO, Avendaño JGF (2017). Therapeutic L-asparaginase: upstream, downstream and beyond. Critical Reviews in Biotechnology 37: 82-99. DOI 10.3109/07388551.2015.1120705.

Manan M, Webb C (2017). Design aspects of solid state fermentation as applied to microbial bioprocessing. Journal of Applied Biotechnology \& Bioengineering 4: 00094.

Meghavarnam AK, Janakiraman S (2017). Solid state fermentation: an effective fermentation strategy for the production of Lasparaginase by Fusarium culmorum (ASP-87). Biocatalysis and Agricultural Biotechnology 11: 124-130. DOI 10.1016/j. bcab.2017.06.001.

Mishra A (2006). Production of L-asparaginase, an anticancer agent, from Aspergillus niger using agricultural waste in solid state fermentation. Applied Biochemistry and Biotechnology 135: 33-42. DOI 10.1385/ABAB:135:1:33.

Mitchell DA, Von Meien OF, Luz LFL, Berovič M (2006). The scaleup challenge for SSF bioreactors. In: Mitchell DA, Berovič M, Krieger N, eds. Solid-State Fermentation Bioreactors. Berlin, Heidelberg: Springer.

Mohan Kumar NS, Ramasamy R, Manonmani HK (2013). Production and optimization of L-asparaginase from Cladosporium sp. using agricultural residues in solid state fermentation. Industrial Crops and Products 43: 150-158. DOI 10.1016/j.indcrop.2012.07.023.
Moola ZB, Scawen M, Atkinson T, Nicholls D (1994). Erwinia chrysanthemi L-asparaginase: epitope mapping and production of antigenically modified enzymes. Biochemical Journal 302: 921-927. DOI 10.1042/bj3020921.

Nageswara S, Guntuku G, Tadimalla P (2014). Production of Lasparaginase by solid state fermentation using marine fungus. BioMed Res (Internet): 1-9.

Narayana K, Kumar K, Vijayalakshmi M (2008). L-asparaginase production by Streptomyces albidoflavus. Indian Journal of Microbiology 48: 331-336. DOI 10.1007/s12088-008-0018-1.

Narta UK, Kanwar SS, Azmi W (2007). Pharmacological and clinical evaluation of L-asparaginase in the treatment of leukemia. Critical Reviews in Oncology/Hematology 61: 208-221. DOI 10.1016/j.critrevonc.2006.07.009.

Nee'nigam PS, Pandey A (2009). Solid-state fermentation technology for bioconversion of biomass and agricultural residues. In: Nee'nigam PS, Pandey A, eds. Biotechnology for AgroIndustrial Residues Utilisation. Dordrecht: Springer.

Ooijkaas LP, Weber FJ, Buitelaar RM, Tramper J, Rinzema A (2000). Defined media and inert supports: their potential as solid-state fermentation production systems. Trends in Biotechnology 18: 356-360. DOI 10.1016/S0167-7799(00)01466-9.

Pandey A, Selvakumar P, Ashakumary L (1996). Performance of a column bioreactor for glucoamylase synthesis by Aspergillus niger in SSF. Process Biochemistry 31: 43-46. DOI 10.1016/ 0032-9592(94)00050-6.

Parekh S, Vinci V, Strobel R (2000). Improvement of microbial strains and fermentation processes. Applied Microbiology and Biotechnology 54: 287-301. DOI 10.1007/s002530000403.

Pedreschi F, Mariotti S, Granby K, Risum J (2011). Acrylamide reduction in potato chips by using commercial asparaginase in combination with conventional blanching. LWT-Food Science and Technology 44: 1473-1476. DOI 10.1016/j.lwt.2011.02.004.

Pokrovskaya M, Aleksandrova S, Pokrovsky V, Omeljanjuk N, Borisova A, Anisimova NY, Sokolov N (2012). Cloning, expression and characterization of the recombinant Yersinia pseudotuberculosis L-asparaginase. Protein Expression and Purification 82: 150-154. DOI 10.1016/j.pep.2011.12.005.

Pramod T, Lingappa K (2008). Immobilization of Aspergillus niger in polyurethane foam for citric acid production from carob pod extract. American Journal of Food Technology 3: 252-256. DOI 10.3923/ajft.2008.252.256.

Pritsa A, Papazisis K, Kortsaris A, Geromichalos G, Kyriakidis D (2001). Antitumor activity of L-asparaginase from Thermus thermophilus. Anti-cancer Drugs 12: 137-142. DOI 10.1097/ 00001813-200102000-00007.

Shakambari G, Ashokkumar B, Varalakshmi P (2019). Lasparaginase-a promising biocatalyst for industrial and clinical applications. Biocatalysis and Agricultural Biotechnology 17: 213-224. DOI 10.1016/j.bcab.2018.11.018.

Soccol CR, Costa ESFD, LaJ Letti, Karp SG, Woiciechowski AL, Vandenberghe LPDS (2017). Recent developments and innovations in solid state fermentation. Biotechnology Research and Innovation 1: 52-71. DOI 10.1016/j. biori.2017.01.002.

Souza PM, De Freitas MM, Cardoso SL, Pessoa A, Guerra ENS, Magalhães PO (2017). Optimization and purification of 1asparaginase from fungi: a systematic review. Critical Reviews in Oncology/Hematology 120: 194-202. DOI 10.1016/j.critrevonc.2017.11.006.

Sreenivasulu V, Jayaveera KN, Rao PM (2009). Solid-state fermentation for the production of $\mathrm{L}$-asparaginase by 
Aspergillus Sp. Research Journal of Pharmacognosy and Phytochemistry 1: 21-25.

Supriya GNR, Rudhrapati P, Audipudi AV (2015). Production of L-asparaginase by Aspergillus melleus AVNR-1 under solid state fermentation using agro-industrial wastes. International Journal of Advanced Research in Chemical Science 2: 29-36.

Thirunavukkarasu N, Gummadi SN, Suryanarayanan TS, Murali TS, Ravishankar JP, Gummadi SN (2011). L-asparaginase from marine derived fungal endophytes of seaweeds. Mycosphere 2: $147-155$.

Thomas L, Larroche C, Pandey A (2013). Current developments in solid-state fermentation. Biochemical Engineering Journal 81: 146-161. DOI 10.1016/j.bej.2013.10.013.

Uppuluri KB, Dasari RKV, Sajja V, Jacob AS, Reddy DSR (2013). Optimization of $\mathrm{L}$-asparaginase production by isolated Aspergillus niger $\mathrm{C} 4$ from sesame (black) oil cake under SSF using Box-Behnken design in column bioreactor.
International Journal of Chemical Reactor Engineering 11: 103-109.

Vala AK, Dave BP (2016). L-Asparaginases from fungi: a mini review. Journal of Bacteriology \& Mycology: Open Access 3: 181-182.

Vivekananda S, Sankareswaran M, Prabhavathi P (2013). A novel role of L-asparaginase enzyme production from fungal species. Journal of Microbiology and Biotechnology Research 3: 7-14.

Yun MK, Nourse A, White SW, Rock CO, Heath RJ (2007). Crystal structure and allosteric regulation of the cytoplasmic Escherichia coli L-asparaginase I. Journal of Molecular Biology 369: 794-811. DOI 10.1016/j.jmb.2007.03.061.

Zhu Y, Smits J, Knol W, Bol J (1994). A novel solid-state fermentation system using polyurethane foam as inert carrier. Biotechnology Letters 16: 643-648. DOI 10.1007/ BF00128615.

Zuo S, Zhang T, Jiang B, Mu W (2015). Recent research progress on microbial L-asparaginases. Applied Microbiology and Biotechnology 99: 1069-1079. DOI 10.1007/s00253-014-6271-9. 